\title{
Synthesis of Cobalt-Complex Azo Dye from 2, 2[Benzene-1, 3-diyl di-(E)-diazene-2, 1-diyl] bis (4-nitroaniline)
}

\author{
Y. B. Taura ${ }^{1}$, S. M. Gumel, ${ }^{2 *}$ S. Habibu ${ }^{3}$ and J. L. Adam ${ }^{2}$ \\ ${ }^{I}$ Department of Fashion Design and Clothing Technology, Hussain Adamu Federal Polytechnic, Kazaure, \\ Jigawa State - Nigeria \\ ${ }^{2}$ Department of Pure and Industrial Chemistry, Bayero University, Kano- Nigeria \\ ${ }^{3}$ Department of Chemistry, Federal University, Dutse Jigawa State - Nigeria
}

\begin{abstract}
The aim of this investigation is to carry out the synthesis of bisazo dye 2, 2[benzene-1, 3-diyl di (E) diazene 2, 1-diyl] bis (4-nitroaniline). The synthesis was conducted through the diazotization and coupling of mphenylene diamine with 4-nitroanline leading to the production of azo metal (II) complex of Cobalt. Characterization of the ligand and the metal complex was carried out using various 34hysic-chemical techniques. The metal chelates have a metal to ligand ratio of 1:1. The synthesized azo metal (II) complex dye had a potential application for high density optical recording media due to their good absorption spectra and high thermal stability.
\end{abstract}

Key Words: Azo dye, Ligand, Metal Complex, UV-Visible Spectroscopy

\section{Introduction}

Vast quantity of dyes are annually produced and consumed in many different industries all over the world, which include pharmaceuticals, cosmetics, food, leather, paper, and textiles [1]. Dyes are coloured compounds, they absorbed light in the visible region of the spectrum $(400-700 \mathrm{~nm})$ and posses at least one colour bearing group (chromophore). Have a conjugated structural set-up (presence of alternating single and double bonds) and exhibit resonance of electrons [2]. In addition to these features they also carry auxochromes, usually carboxylic acid, sulphonic acid, amino, or hydroxyl groups. The auxochromes are used to shift the colour of a colourant and often assist in influencing the solubility of the dye.

The three most common chemical groups used in the production of dyes are anthraquinone, phthalocyanine and azo groups [3]. Azo groups are by far the most important and they represent the major and most versatile class of synthetic dyes [4]. Azo dyes have been widely studied in recent years because of ease of availability, reasonable price and applied utilities [5]. The wider applications of these dyes results from a combination of the properties of azo groups and several types of the aromatic- substituted ligand that confer to them intense colour over the whole visible range. These dyes have been exploited for non-linear optical usage when they contain substituent groups on the aromatic rings with push-pull electron ability [6]. Azo dyes have excellent thermal and optical properties and widely applied in areas such as optical recording medium [7], toner [8], inkjet printing [9] and oil soluble light fast dyes [10].

Recently azo metal chelates have been given increasing attention as a result of their fascinating geometrical and electronic properties which inform the possibility of their application in molecular memory storage [7]. In comparison with dyes themselves metal complex azo dyes are more light-stable and allow for easier control of the wavelength through careful selection of suitable substituent groups [11]. This informs the fact that the thermal stability and the suitable absorption band of azo compound provide the essential properties for their application as high-density optical recording materials.

Literature survey suggest that quite a number of azo dyes have been studied by many workers [8], as chelating agents and their metal chelates have been extensively used in the textile industries. Azo dyes have a general structure $\mathrm{R}-\mathrm{N}=\mathrm{N}-\mathrm{R}$, where $\mathrm{R}$ and $\mathrm{R}$ are aryl, alkyl, or heterocyclic groups. They are usually prepared through condensation of azo compounds with ketones or aldehydes. Numerous researches have been carried out on the synthesis of mono azo dyes as reported in the reviews but very little comparative investigations was conducted on diazo dyes.

In the present investigation the synthesis of bisazo dyes derived from m-phenylene diamine and 4nitroaniline as coupling components and its metal complex is described. The spectral observations and physicochemical analysis of the synthesized compounds are discussed.

\section{Experimental} purification.

All the chemicals and the solvents used were of analytical grade and therefore need no further 


\section{Synthesis of the Ligand}

$1.08 \mathrm{~g} / 0.01 \mathrm{~mol}$ of m-phenylene diamine was dissolved in a mixture of $5 \mathrm{~cm}^{3}$ of water and $10 \mathrm{~cm}^{3}$ of concentrated hydrochloric acid. While $20 \mathrm{ml}$ of concentrated hydrochloric acid was diluted with about $60 \mathrm{~g}$ of crushed ice to which $2.5 \mathrm{~g}$ of sodium nitrite dissolved in $10 \mathrm{ml}$ of water was added. The m-phenylene diamine hydrochloric acid solution was then added immediately. The mixture was stirred continuously over a period of one hour until a dark yellow coloured (tetra azo) solution is obtained. The coupling agent (p-nitro aniline) dissolved in $0.02 \mathrm{~mol}$ DMF cooled with ice blocks to a temperature of $5^{\circ} \mathrm{C}$ is slowly added with continuous stirring to the tetra azo solution. A solution of sodium acetate is then stirred in to the mixture until neutralization was achieved. The dye is washed thoroughly with water and collected by filtration [12].

\section{Synthesis of the Metal (II) complex}

$4 \mathrm{mmol}$ of metal acetate solution in $10 \mathrm{ml}$ of methanol was added to methanol-chloroform $(1: 1 \mathrm{v} / \mathrm{v})$ solution containing $8 \mathrm{mmol}$ of ligand and was refluxed for 2 hours and kept at room temperature. The precipitated complex was filtered, washed with methanol and then recrystallized from 1:3v/v methanol-chloroform mixture and dried.

\section{UV-Visible Spectroscopy}

The electronic spectra were measured by means of a Shimadzu 1601 Spectrophotometer in the region 200-800nm [13].

\section{Results and Discussion}

The proposed synthetic scheme for the metal complex and its precursor ligand is outlined below:
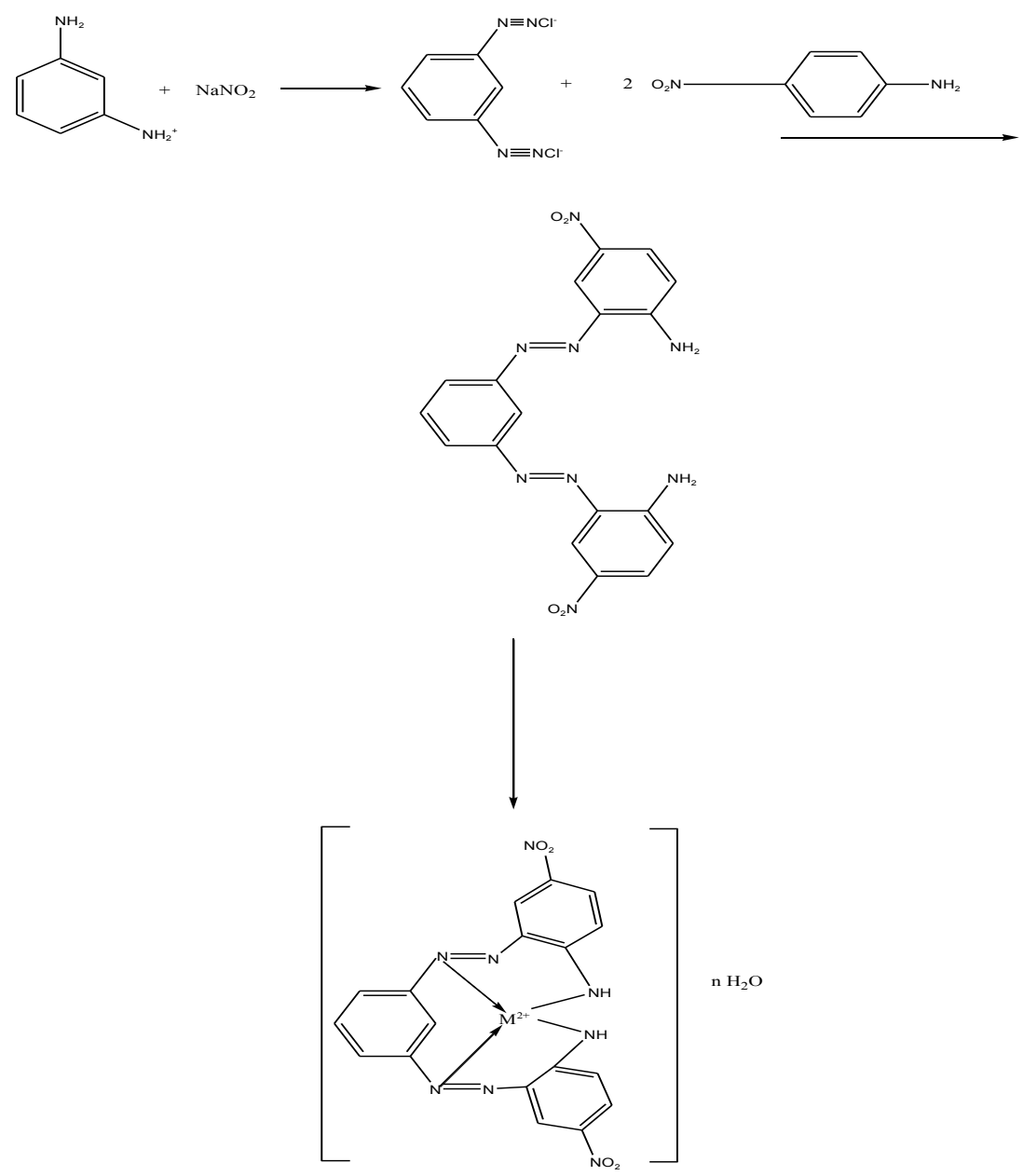

$\mathrm{M}^{2+}=\mathrm{Co}$ Synthesis of metal (II) Comlex

Figure 1: General Routes for Synthesis of the Ligand

The table below shows the micro-analytical investigation results for the syntheisized ligand and the metal complex. 
Synthesis of Cobalt-Complex Azo Dye from 2, 2[Benzene-1, 3-diyl di-(E)-diazene-2, 1-diyl] bis

Table 1: Micro analytical data of ligand and metal complexes

\begin{tabular}{|l|l|l|l|l|}
\hline Name of compound & $\begin{array}{l}\text { Yield } \\
\%\end{array}$ & Colour & M.P. ${ }^{\circ} \mathrm{C}$ & $\begin{array}{l}\text { Decomposition } \\
\text { Temperature }\left({ }^{\circ} \mathrm{C}\right)\end{array}$ \\
\hline Ligand (L) & 68 & Reddish brown & 94 & 130 \\
\hline${\mathrm{L}-\mathrm{Co}^{2+}}^{2+}$ & Deep brown & 280 & 250 \\
\hline
\end{tabular}

The synthesized compound was an intensely amorphous solid. The ligand and the metal complex decompose at 130 and $250{ }^{\circ} \mathrm{C}$ respectively. It was found that the thermal stability of the metal complex was higher than that of the ligand. Azo dyes posses good thermal stability,

\section{Solubility of the Synthesized Compounds} below:

The solubility tests results of the synthesized ligand and the metal complex is presented in the table

Table 2: Solubility Test

\begin{tabular}{|l|l|l|}
\hline Solvent & Ligand (L) & L-Co $^{\mathbf{2}}$ \\
\hline Methanol & Soluble & Not soluble \\
\hline Chloroform & Soluble & Not soluble \\
\hline DMSO & Soluble & Soluble \\
\hline DMF & Slightly soluble & Soluble \\
\hline Water & Slightly soluble & Not soluble \\
\hline
\end{tabular}

The ligand was soluble in methanol, chloroform and dimethylsulfoxide but the metal complex was not in methanol but soluble in dimethylsulfoxide and dimethylformide. The good solubility of the azo-metal chelates makes them suitable for use as optical medium [14].

\section{UV-Visible Spectroscopy}

This technique was employed in order to determine the wavelength of maximum absorption $\left(\lambda_{\max }\right)$ for the synthesized dyes. Results obtained are presented in table below.

Table 3: UV-VIS Spectra in DMSO

\begin{tabular}{|l|l|l|}
\hline Compound & Ligand(L) & L-Co $^{2+}$ \\
\hline $\boldsymbol{\lambda}_{\max }(\mathbf{n m})$ & 264.47 & 270.01 \\
& 397.97 & 39958 \\
\hline Absorbance & 0.335 & 0.776 \\
\hline
\end{tabular}

The $\chi \max$ of the ligand was around $264 \mathrm{~nm}$ and $398 \mathrm{~nm}$ while that of the metal complex was $270 \mathrm{~nm}$ and 398nm.

The UV-VIS spectra of synthesized azo dye and its metal complexes showed two bands between 264-398nm and 270-398nm. The first band maybe due to $\pi-\pi^{*}$ transition within the aromatic ring and the second band would be due to $n-\pi^{*}$ transition of $\mathrm{N}=\mathrm{N}$ group. The formation of metal (II) azo complexes was also confirmed by their UV-VIS spectra. It can be seen that $\lambda$ max of azo dye was at around 264 and $398 \mathrm{~nm}$. While the $\lambda$ max of complexes were slightly blue shifted which arise from the energy change of intense $\pi-\pi^{*}$ and n$\pi^{*}$ transition of the conjugated chromophore due to the chelation between metal ions and azo ligand. The complexation of the dye with the metal ion was responsible for a significant hypochromic shift at both $\pi$ - $\pi^{*}$ and $\mathrm{n}-\pi^{*}$ transition region [15]. In metal chelates, the light absorption is believed to take place in the UV region as a result of absorption arising from electronic transition in a conjugated system, where a metal may or may not participate. These types of absorptions are referred to as $\mathrm{K}$ type and have been studied by a number of workers [16]. Absorption bands in the UV region due to forbidden transitions and the ligand K type band characteristics in visible region have been extensibly studied by researchers [17].

\section{Conclusion}

It can be concluded that the synthesized azo metal (II) complex has potential application for high density optical recording media due to their good absorption spectra and high thermal stability. The result from the elemental analysis and spectral observation indicated that the ligand is coordinated to the metal atom as monodentate in the ratio of $1: 1$.

\section{References}

[1]. F. Rath, J.D. Hall, and C.E. Cernigila, Mutagenicity of azo dyes used in Foods, Drugs and Cosmetics before and after reduction by clostridium species from the human intestinal tract. Food Chem. Toxicol 35, 1997, 897-901

[2]. E. N. Abrahart, Dyes and Their Intermediates. New York: Chemical Publishing 1977, pp 1-2

[3]. H. Keharia, H. Patel, and D. Madamwar Decolourisation Screening of Synthetic Dyes by Anaerobic Methanogenic Sludge Using Batch Decolourisation Assay. World J. Microbial Biotechnol, 20, 2004, 365-370. 
[4]. S.K. Mohammed, A.M. Nour, and D. El Solid State Photolysis of Triazene I-Oxide with Napthols. Synthesis of Azo Dyes, J. Chem. Res. 8, 1999,508-509

[5]. B.L. Feringa, R.A. Van Delden, N. Koumu, E.M. Geertsema, S.Y. Kawata, and K. Nakatan Chem. Rev. 100, 2000, 1777-1789

[6]. V.P. Shibaev Ed. S Pringer: Berlin, 1996, 37-110

[7]. T. Abe S.Mano Y. Yamoda and A. Tomotake J. Imag. Sci. Tech. 43, 1999, 339-344

[8]. K. .Maho, T. Shintaro, K. Yutaka, W. Kazuo. N. Toshiyuki and T. Mosahiko. Jpn. J. Text. Res. $24,1990,114142$.

[9]. G. Hallas and J.H. Choi. Dyes and Pigments, 40, 1999, 119-129

[10]. S.S. Kandil Trans. Met. Chem. 23, 1998, 461-465

[11]. Y. Suziki, Y. Okamoto, Y. Kurose Maeda, and S. High. High Speed Recording Performance of Metal Azo Dye Containing Digital Video-Recordable Discs. Japanese Jour. of Appl. Phys. 38; 1999, 1669-74

[12]. K. R. Anitha., R. Venugopala, and K. S. Rao, Synthesis and antimicrobial evaluation of Metal (II) complexes of a novel bisazo dye 2,21[benzene-1,3-diyl di (E) diazene2,1-diyl] bis (4-chloroaniline) J. Chem. Pharm. Res., 3 (3): 2011, 511-519

[13]. G. Gauglitz and T. Vo-Dinh Hand book of spectroscopy (Wiley-VCH 2003).

[14]. S. Haifen, C. Kongchang, W. Dongqing, and T. He, Dyes and Pigments 60, 2004,111-119

[15]. A. .J. Kasawaki, , Chem. Soc. Perkins Trans 2; 1990, 223

[16]. J. Lewis and R.G. Wilkins, Modern Co-ordination Chem. Inter Science, New York, , 1956, 427

[17]. Calvin and Coworkers, J. Amer. Chem. Soc. 2278, 68, (1946). J. Inorg. And Nuclei Chem.11,2 (1956) 